\title{
IODINE STATUS OF PREGNANT WOMEN RESIDING IN URBAN SLUMS IN DELHI
}

\section{SPRIHA RAO ${ }^{1}$, GURUDAYAL SINGH TOTEJA ${ }^{1,2 *}$, NEENA BHATIA ${ }^{3}$, SUPRIYA DWIVEDI ${ }^{1}$, ZAOZIANLUNGLIU GONMEI ${ }^{1}$, ASHOK KUMAR ROY ${ }^{1}$}

${ }^{1}$ Centre for Promotion of Nutrition Research and Training with Special Focus on North-East, Tribal and Inaccessible Population (Indian Council of Medical Research), New Delhi, India. ${ }^{2}$ Desert Medicine Research Centre (Indian Council of Medical Research), Jodhpur, Rajasthan, India. ${ }^{3}$ Department of Food and Nutrition, Lady Irwin College, University of Delhi, New Delhi, India. Email: gstoteja@gmail.com

Received: 29 January 2018, Revised and Accepted: 11 May 2018

\section{ABSTRACT}

Objectives: The present study was carried out to determine the iodine nutrition status among pregnant women in slums of West Delhi.

Methods: A community-based cross-sectional study was carried out among the third-trimester pregnant women residing in urban slums of West Delhi. Urinary iodine concentration was estimated using ammonium persulfate method, and salt iodine was estimated using iodometric titration.

Results: Of the total 180 pregnant women, 70.6\% were consuming adequately iodized salt (iodine levels $\geq 15$ ppm). Median urinary iodine level for the pregnant women was $147.5 \mu \mathrm{g} / \mathrm{L}$ indicating iodine deficiency among this group. A total of $51.1 \%$ of women had urinary iodine levels $<150 \mu \mathrm{g} / \mathrm{L}$.

Conclusion: Pregnant women belonging to slum community from Delhi have a suboptimal iodine status. Further, the proportion of women consuming iodized salt is less than the national average indicating the need to educate these women about the importance of iodine during pregnancy.

Keywords: Iodine, Urinary iodine, Iodized salt, Pregnant women.

(c) 2018 The Authors. Published by Innovare Academic Sciences Pvt Ltd. This is an open access article under the CC BY license (http://creativecommons. org/licenses/by/4. 0/) DOI: http://dx.doi.org/10.22159/ajpcr.2018.v11i7.25002

\section{INTRODUCTION}

Iodine deficiency is a major public health problem and has been described as world's single greatest cause of preventable brain damage and mental retardation [1]. Iodine is an essential trace element required for the synthesis of thyroid hormones, which, in turn, regulates the metabolic pattern of most cells and hence plays an important role in the process of growth and development of most organs, especially the brain $[2,3]$. The most critical period is from the second trimester of pregnancy to the $3^{\text {rd }}$ year after birth [1].

Studies have indicated that people living in areas affected by iodine deficiency may have lower intelligence quotient, by as much as 13.5 points than those living in areas with no deficiency [4]. Other consequences of iodine deficiency include cretinism, growth retardation, neonatal hypothyroidism, congenital abnormalities, increased pregnancy loss, and infant mortality [5].

The requirement of iodine during pregnancy increases by over $50 \%$ because of increased thyroid hormone production, increased renal losses of iodine and transfer of iodine to the fetoplacental unit $[6,7]$. Consequently, the recommended dietary intake of iodine is higher in pregnancy $(250 \mu \mathrm{g} /$ day $)$ as compared to a normal adult (150 $\mu \mathrm{g} /$ day) [1].

Despite decades of efforts and programs to control iodine deficiency, such as salt iodization, it remains a significant public health problem in 47 countries, affecting a total of 2 billion people worldwide [8]. The soil of the Indian subcontinent is deficient in iodine resulting in large parts of its population being at risk for iodine deficiency disorders (IDDs). As per the surveys conducted by the Directorate General of Health Services, Indian Council of Medical Research, Health Institutions, and the State Health Directorates, of a total of 414 districts surveyed in all the 29 states and 7 UTs, 337 districts were found to be endemic, i.e., where the prevalence of IDDs is more than $5 \%[9]$.
The present survey was, therefore, conducted focusing on the iodine status of pregnant women from slums of Delhi and assessed their access to adequately iodized salt.

\section{METHODS}

The study was carried out in Kirti Nagar slums of West Delhi, which is a notified slum colony as per the "Delhi Urban Shelter Improvement Board" under Government of NCT of Delhi with a total population of approximately 50,000. Inhabitants of the cluster are mostly from the states of Uttar Pradesh and Bihar. The third-trimester pregnant women (gestational age $>28$ weeks) who met the inclusion criteria of voluntary participation and were apparently healthy were enrolled for the study. Women with multiple fetuses, history of chronic diseases, receiving blood transfusion during current pregnancy and those taking micronutrient supplements except iron-folic acid tablets were excluded from the study.

Ethics Committee Clearance was obtained from Lady Irwin College, University of Delhi, before the initiation of the study. Written informed consent was obtained from each subject at enrollment. The data presented in this paper formed the baseline data for a longitudinal study to assess the nutritional status during pregnancy and its association with birth outcome.

Random urine sample was collected from pregnant women. A total of 20-30 ml of urine sample were collected in a wide mouth plastic bottle of $50 \mathrm{ml}$ capacity. After collection, the bottle was tightly capped and sealed with parafilm to avoid leakage. The urine samples were stored in the refrigerator at $4^{\circ} \mathrm{C}$ in the laboratory until analysis. Edible salt samples were collected from the households of pregnant women. Around $50 \mathrm{~g}$ of salt was collected and packed into air-tight zip lock pouches and was kept at room temperature. Urinary iodine was estimated using Sandell and Kolthoff method, and salt iodine was estimated using iodometric titration method as recommended by the WHO [1]. 
The iodine estimation was carried out at "Centre for Promotion of Nutrition Research and Training, with special focus on NorthEast, Tribal and Inaccessible Population" (Indian Council of Medical Research), New Delhi. The laboratory of the center is accredited by National Accreditation Board of Testing and Calibrating laboratories under ISO 15189:2007. Strict internal and external quality control measures were followed. Internal quality control was maintained using standards and controls with every batch of samples, and for external quality control, the laboratory was enrolled with Centers for Disease Control and Prevention, Atlanta for urinary iodine (Ensuring the Quality of Urinary Iodine Procedures Programme).

\section{RESULTS}

A total of 188 pregnant women (mean age: $24.7 \pm 4.5$ years) were recruited under the study. Both urine and salt samples were collected for only 180 pregnant women, who formed the study group. None of the pregnant women were found to have either palpable or visible goiter on examination.

A total of $70.6 \%$ of the pregnant women were found having adequately iodized salt (i.e., with iodine levels $\geq 15 \mathrm{ppm}$ at household level). A total of $12.2 \%$ pregnant women were consuming non-iodized salt and $17.2 \%$ were consuming inadequately iodized salt (iodine levels of $<15 \mathrm{ppm}$ ) (Table 1).

Median urinary iodine (MUI) levels in population and salt iodine content have been recommended as an indicator to monitor the progress of IDD elimination through the supply of universally iodized salt. A median level between $150 \mathrm{mg} / \mathrm{l}$ and $249 \mathrm{mg} / \mathrm{l}$ among pregnant women indicates population which has no iodine deficiency [1].

Under the present study, the MUI levels were found to be $147.5 \mathrm{mg} / \mathrm{l}$ indicating a deficient iodine status (Table 2). The percentage of women having iodine levels $<50 \mathrm{mg} / \mathrm{l},<100 \mathrm{mg} / \mathrm{l}$, and $<150 \mathrm{mg} / \mathrm{l}$ was $13.9 \%$, $35 \%$, and $51.1 \%$, respectively.

\section{DISCUSSION}

Urinary iodine level is a marker of iodine nutritional status [10]. In the present study, the MUI level among pregnant women residing in slums of Delhi was $147.5 \mu \mathrm{g} / \mathrm{l}$, which is less than the cutoff levels implying that IDD is a public health problem in this section of the community. Further, nearly $30 \%$ of the women were consuming either non-iodized or inadequately iodized salt contributing to inadequate dietary intake of iodine.

Similar findings with high prevalence of IDD have been reported by various previous studies across the country. A hospital-based study among 829 pregnant women from slum areas of Delhi reported iodine deficiency (defined as UI $<100 \mu \mathrm{g} / \mathrm{L}$ ) in $23 \%$ of women [11]. Another study in 151 rural adolescent pregnant mothers belonging to low socioeconomic status (SES) from Uttaranchal, reported MUI

Table 1: Iodization level of edible salt samples

\begin{tabular}{llll}
\hline $\begin{array}{l}\text { Total number of salt } \\
\text { samples }\end{array}$ & \multicolumn{3}{l}{ Iodine level (ppm) $\mathbf{n}(\mathbf{\%})$} \\
\cline { 2 - 4 } & $\mathbf{0}$ & $<\mathbf{1 5}$ & $\mathbf{2 1 5}$ \\
\hline 180 & $22(12.2)$ & $31(17.2)$ & $127(70.6)$ \\
\hline
\end{tabular}

as $95 \mu \mathrm{g} / \mathrm{L}$; with a goiter rate of $14.6 \%$ [12]. Singh et al., 2009, reported low level of MUI levels $(117.5 \mu \mathrm{g} / \mathrm{L})$ among pregnant women from 28 villages of Jodhpur, Rajasthan. Further, a high proportion of women (80.8\%) were consuming salt, having inadequate iodine content [13]. A study among tribal women from Nagpur, Maharashtra, reported MUI levels of 106 and $71 \mu \mathrm{g} / \mathrm{L}$ in the second and third trimester of pregnancy, respectively [14]. Another study from Kolkata among 237 low SES pregnant women attending an antenatal clinic reported $37 \%$ women having insufficient iodine nutrition (UI < $150 \mu \mathrm{g} / \mathrm{l}$ ) [15].

In contrast to the above studies, some recent studies suggest an improved status of iodine nutriture. A hospital-based study among 150 pregnant women in Delhi reported sufficient iodine nutriture with UI levels in the first, second, and third trimesters as 285,318 , and $304 \mu \mathrm{g} / \mathrm{L}$, respectively [16]. Another longitudinal study carried out among pregnant women from Pune reported MUI concentrations as $203 \mu \mathrm{g} / \mathrm{L}$ and $211 \mu \mathrm{g} / \mathrm{L}$ at 17 and 34 weeks gestation, respectively [17]. Similarly, MUI levels of $260 \mu \mathrm{g} / \mathrm{L}$ were reported, in 2017, among 1031 women attending antenatal Clinic of a Secondary Care hospital in Faridabad, Haryana [18].

The gradual improvement in the iodine nutriture of pregnant women as indicated by the recent studies could be due to increased availability of iodized salt to the population over the period. A countrywide evaluation conducted under National Family Health Survey (NFHS)-4, in 2015-16, reported $93 \%$ of the households used iodized salt [19] which is much higher than in NFHS-3 when only $76 \%$ of households were using iodized salt [20]. Further, there was a steady increase in the use of iodized salt by household wealth quintiles, from $90 \%$ in the lowest wealth quintile to $98 \%$ in the highest wealth quintile. Furthermore, the percentage of households using iodized salt was more than the national average in Delhi (98.5\%) [19]. The present study reported $87.8 \%$ of the pregnant women from the low-income strata to be consuming iodized salt, which is in line with the NFHS data.

\section{CONCLUSION}

The present study indicates iodine deficiency among pregnant women from lower SES. However, the results of the study may not be generalized due to the small sample size and convenient sampling in urban slum setting. Further studies with sufficient sample size are required to validate the findings and form the basis for necessary interventions.

\section{ACKNOWLEDGMENTS}

We acknowledge and thank the Director General, ICMR for granting a Senior Research Fellowship to the first author for carrying out the work as part of their Ph.D. The facilities provided by ICMR for biochemical analysis is also acknowledged. We are also grateful to the women who participated in the study.

\section{AUTHORS' CONTRIBUTIONS}

Dr. Spriha Rao, Dr. Neena Bhatia, and Dr. G.S Toteja were involved in conceptualizing of the study, acquisition, analysis, and interpretation of data as well as drafting the manuscript. Supriya Dwivedi, Zaozianlungliu Gonmei, and Ashok Kumar Roy were involved in the interpretation of data.

\section{CONFLICTS OF INTEREST}

The authors declare that there are no conflicts of interest.

Table 2: Distribution pattern of urinary iodine level $(\mu \mathrm{g} / \mathrm{l})$ among pregnant women

\begin{tabular}{lllllll}
\hline Total number of pregnant women & Median level $(\boldsymbol{\mu g} / \mathrm{l})$ & \multicolumn{5}{c}{ Distribution of urinary iodine level $(\boldsymbol{\mu g} / \mathbf{l}) \mathbf{n}(\%)$} \\
\cline { 3 - 7 } & & $<\mathbf{5 0}$ & $\mathbf{5 0 - 9 9}$ & $\mathbf{1 0 0 - 1 9 9}$ & $\mathbf{2 0 0 - 3 9 9}$ & $\mathbf{2 4 0 0}$ \\
\hline 180 & 147.5 & $25(13.9)$ & $38(21.1)$ & $58(32.2)$ & $43(23.9)$ & $16(8.9)$ \\
\hline
\end{tabular}

$\mathrm{N}$ : Number of subjects with indicated level of urinary iodine 


\section{REFERENCES}

1. WHO/UNICEF/ICCIDD. Assessment of Iodine Deficiency Disorders and Monitoring their Elimination. A Guide for Programme Managers. $3^{\text {rd }}$ ed. Geneva: World Health Organisation; 2007.

2. Bernal J, Nunez J. Thyroid hormones and brain development. Eur J Endocrinol 1995; 133:390-8.

3. Chan S, Kilby MD. Thyroid hormone and central nervous system development. J Endocrinol 2000;165:1-8

4. Bleichrodt N, Born MP. A metaanalysis of research on iodine and its relationship to cognitive development. In: Stanbury JB, editor. The damaged brain of Iodine Deficiency. New York, USA: Cognizant Communication Corporation; 1994. p. 195-200.

5. Boyages SC, Halpern JP. Endemic cretinism: Toward a unifying hypothesis. Thyroid 1993;3:59-69.

6. Glinoer D. Pregnancy and iodine. Thyroid 2001;11:471-81

7. Hebbar S, Kumar S, Amin S, Doizode S. Subclinical hypothyroidism in pregnancy; Is there a need for pharmacological intervention? Int $\mathrm{J}$ Pharm Pharm Sci 2017;9:186-91

8. de Benoist B, McLean E, Andersson M, Rogers L. Iodine Deficiency in 2007: Global progress since 1993. Food Nutr Bull 2008;29:195-202.

9. Directorate General of Health Services, National Iodine Deficiency Disorders Control Programme, MOHFW, Govt of India, New Delhi. Last Updated 2017 July 6. Available from: http://www.dghs.gov.in/ content/1348_3 NationalIodineDeficiency.aspx. [Last accessed on 2018 Jan 17].

10. Sarkar D, Chakraborty A, Bhattacharya C, Singh L, Chandra A. Exploration of goitrogenic/antithyroidal potentiality of bamboo-shoots in relation to thiourea. Int J Pharm Pharm Sci 2017;9:7-12.
11. Kapil U, Pathak P, Tandon M, Singh C, Pradhan R, Dwivedi SN. Micronutrient deficiency disorders amongst pregnant women in three urban slum communities of Delhi. Indian Pediatr 1999;36:983-9.

12. Pathak P, Singh P, Kapil U, Raghuvanshi RS. Prevalence of iron, vitamin $\mathrm{A}$, and iodine deficiencies amongst adolescent pregnant mothers. Indian J Pediatr 2003;70:299-301.

13. Singh MB, Fotedar R, Lakshminarayana J. Micronutrient deficiency status among women of desert areas of western Rajasthan, India. Public Health Nutr 2009;12:624-9.

14. Menon KC, Skeaff SA, Thomson CD, Gray AR, Ferguson EL, Zodpey S, et al. The Effect of maternal iodine status on infant outcomes in an iodine-deficient Indian population. Thyroid 2011;21:1373-80.

15. Majumder A, Jaiswal A, Chatterjee S. Prevalence of iodine deficiency among pregnant and lactating women: Experience in Kolkata. Indian J Endocrinol Metab 2014;18:486-90.

16. Grewal E, Khadgawat R, Gupta N, Desai A, Tandon N. Assessment of iodine nutrition in pregnant north Indian subjects in three trimesters. Indian J Endocr Metab 2013;17:289-93.

17. Lean MI, Lean ME, Yajnik CS, Bhat DS, Joshi SM, Raut DA, et al. Iodine status during pregnancy in India and related neonatal and infant outcomes. Public Health Nutr 2014;17:1353-62.

18. Kant S, Haldar P, Lohiya A, Yadav K, Pandav CS. Status of iodine nutrition among pregnant women attending antenatal clinic of a secondary care hospital: A cross-sectional study from Northern India. Indian J Community Med 2017;42:226-9.

19. National Family Health Survey (NFHS-4), 2015-16, India. International Institute for Population Sciences (IIPS) and ICF; 2017.

20. National Family Health Survey (NFHS-3), 2005-06, India. International Institute for Population Sciences (IIPS) and Macro International; 2007. 